\title{
AOR
}

Selected Papers of \#AolR2021:

The 22nd Annual Conference of the

Association of Internet Researchers

Virtual Event / 13-16 Oct 2021

\section{“THIS ISN'T A PICASSO, IT'S A FERRARI": PRESENTISM, PRECARITY AND DEPENDENCE IN NEW MEDIA ART PRACTICES}

\author{
Roopa Vasudevan \\ Annenberg School for Communication, University of Pennsylvania
}

\section{Extended Abstract}

At the 2018 Eyeo Festival, an annual gathering of practitioners working at the intersection of art and technology, a panel of prominent technologists and artists discussed their relationships with proprietary tools-and the need to consider what values or assumptions are perpetuated through their use (Eyeo Festival, 2018). This is a question that has become increasingly urgent as conversations surrounding technology, ethics, and bias have reached a fever pitch in recent years. More and more, new media artists find themselves re-evaluating the necessity of using proprietary tools, owned by big tech companies with whose policies they do not necessarily agree. (Eyeo Festival, 2018; Thorp, 2018). Ultimately, however, it is difficult to conceive of a techbased art practice that functions without utilizing any of the dominant technologies that we find ourselves surrounded by on a regular basis.

This entanglement was encapsulated by art historian and critic Claire Bishop in 2012; writing for Artforum, she declared that "the digital is, on a deep level, the shaping condition-even the structuring paradox - that determines artistic decisions to work with certain formats and media" (p. 436). However, the tension between artists and technology stretches beyond seemingly autonomous creative choices; it has become especially pronounced in cases such as Twitter's 2018 decision to change their guidelines for developer access to their application programming interface (API). The blog post announcing these changes began, in part, by celebrating the creative and unconventional uses of Twitter adopted by artists and programmers since its initial launch, continuing a long-standing tradition of embracing these "delightful and fun" experiments on the platform (Roth \& Johnson, 2018). However, the rest of the post detailed the tightening requirements the platform was placing on those who might want to use Twitter in similar ways. The new process places a larger burden on developers to provide detailed, up-front descriptions of the functionality of applications, and requires lengthy review by representatives from the platform prior to approval-a stark contrast

Suggested Citation (APA): Vasudevan, R. (2021, October). "This isn't a Picasso, it's a Ferrari":

Presentism, precarity and dependence in new media art practice. Paper presented at AoIR 2021: The 22nd Annual Conference of the Association of Internet Researchers. Virtual Event: AolR. Retrieved from http://spir.aoir.org. 
from previous requirements, where interested developers would automatically receive keys to use the API upon submitting a simple request for a new application (Schwartz, 2018). Developers who already had active applications using the Twitter API would also still be subject to these requirements retroactively (Roth \& Johnson, 2018).

Twitter's post illustrates a pervasive mechanism by which the tech industry utilizes its own power to take control of its technologies back from those who intentionally appropriate, subvert, or modify them, by simultaneously celebrating these actions and altering the system so it becomes harder to do them. As a result, artists who work with technology are inevitably thrust into perpetually shifting situations or environments, controlled by the tech industry, which then directly impact the creation of their work; its longevity; and, often, their own perceptions of it. The fundamental dependence that new media artists have on the interests responsible for developing and controlling dominant technologies connects to larger notions of "perpetual training" necessitated by the societies of control (Deleuze, 1992), which give rise to the industry's ability to manufacture crises that force users to constantly update protocols and devices in order to remain at a habituated stasis (Chun, 2016). While many contemporary art practices are dependent on technological advancement to some extent, artists specifically working with new and emerging technologies are uniquely tied to the cycle of updating and obsolescence: non-compliance typically means that any work they have already created with these tools will cease to function as originally intended (Rinehart \& Ippolito, 2014). As one interviewee for this project put it, this artwork needs to be treated as a Ferrari automobile instead of a Picasso painting-which requires an acceptance of the fact that it needs to be consistently upgraded and maintained, in accordance with established technical protocols, in order to preserve functionality. Thus, it can never be considered "complete" in the same way as a more traditional art piece.

This study represents the beginnings of an investigation into the relationships between new media artists, the tools they use for their work (including data sources and APIs, hardware and software, operating systems, and project storage), and those who control these technologies. I seek to portray this creative community as one that exists in a state of constant uncertainty, and that finds itself in this position at the behest of the tech industry - which both uses artists' work as a way of positioning itself as cuttingedge and original, and as a means of locating potential sites of intentional misuse and subversion. Artists are forced to constantly adapt their processes to the demands of the industry, reinforcing its dominance and, to some extent, undermining any desired critical statement or commentary. By expanding on these ideas, and demonstrating the outsized reliance that artists have on those who control the tools they use, this research also seeks to further trouble assumptions about the existence of this work outside of dominant systems (Monahan, 2015; Hu, 2016) -and, by extension, continue to question whether or not creative subversion or resistance is possible in the ways that artists themselves envision or expect.

This research draws from 20 semi-structured interviews conducted to date with new media artists and creative technologists about their practices and experiences working with technology. The artists' toolkits and media include screen-based computational processes; hardware and electronics; data analysis and the use of APIs; Internet art based in the web browser or in mobile applications; virtual or augmented reality; natural 
language processing, machine learning, and artificial intelligence; or combinations of the above. I also draw from my own practice as a media artist and creative technologist, with personal experience in these areas since 2012.

Preliminary findings from my analysis fall into four broad categories. First, artists consistently rationalize the use of proprietary tools in their work, even when their personal ethical stances would presumably oppose it. Second, artists demonstrate a clear acceptance of instability within the work that they create, and assume by default that their pieces will eventually become out of date, malfunction, or otherwise necessitate some kind of technical upgrading. Third, artists' documentation and archival practices are generally inconsistent, haphazard, and focused on the current moment, reflecting a mentality of presentism built into their processes which assumes constant change and updates. And, finally, many of the artists advocate embracing the ephemeral qualities of their work rather than attempting to stave off the inevitability of obsolescence, which I aim to further explore as a new paradigm through which to examine the creation, experience and preservation of digital and new media artwork.

Together, these findings indicate that the participants' current processes, artistic outputs, and even foundational conceptions of their work's purpose and cultural function are shaped to a large degree by what is afforded to them by those who create and control the technology they use. And often, the restrictions placed on the artist by the technology have the effect of shaping the work in significant ways, sometimes forcing the artist to discard their original plans altogether. Further research will build more on these themes, as well as connect them to a larger conception of the new media artist's role in mainstream technological development and its integration into everyday cultural life.

\section{References}

Bishop, C. (2012). "Digital divide". Artforum, 51(1), 434-441. Retrieved from https://www.artforum.com/print/201207/digital-divide-contemporary-art-and-newmedia-31944.

Chun, W.H.K. (2016). Updating to remain the same: Habitual new media. Cambridge, MA: MIT Press.

Deleuze, G. (1992) Postscript on the societies of control. October, 59, 3-7.

Eyeo Festival [eyeofestival] (2018, August 28). Whose Tools? Whose House? [video file]. Retrieved from https://vimeo.com/287094317.

Hu, T.H. (2016). A prehistory of the cloud. Cambridge, MA: MIT Press.

Monahan, T. (2015). The right to hide? Anti-surveillance camouflage and the aestheticization of resistance. Communication and Critical/Cultural Studies, 12(2), 159-178. DOI: 10.1080/14791420.2015.1006646. 
Rinehart, R. \& Ippolito, J. (2014). Re-collection: Art, new media, and social memory. Cambridge, MA: MIT Press.

Roth, Y. \& Johnson, R. (July 24, 2018). "New developer requirements to protect our platform" [Blog post]. Twitter Developer Blog. Retrieved from https://blog.twitter.com/developer/en_us/topics/tools/2018/new-developerrequirements-to-protect-our-platform.html.

Schwartz, O. (October 16, 2018). "Your favorite Twitter bots are about to die, thanks to upcoming rule changes". Quartz. Retrieved from https://qz.com/1422765/yourfavorite-twitter-bots-are-about-die-thanks-to-upcoming-rule-changes/.

Thorp, J. (February 21, 2018). "Tech and the fine art of complicity". Knight Foundation. Retrieved from https://knightfoundation.org/articles/tech-and-the-fine-art-ofcomplicity. 